\title{
PERCEPÇÕES DO ESTUDANTE COM NECESSIDADES EDUCACIONAIS ESPECIAIS SOBRE A POLITICA DE ACESSIBILIDADE NA UNIVERSIDADE
}

\author{
Zélia Zilda Lourenço de Camargo Bittencourt ${ }^{6}$ \\ Francine Popes de Camargo ${ }^{7}$
}

\section{RESUMO}

$\mathrm{O}$ direito ao acesso à educação regular tem sido tema recorrente nas discussões em vários órgãos educacionais. Garantir não só o acesso, mas principalmente a permanência de pessoas com algum tipo de deficiência nas universidades extrapolam a questão da adequação das instalações físicas. Esta investigação se propôs a conhecer as percepções dos alunos universitários com necessidades educacionais especiais sobre as condições de inclusão e acessibilidade da Universidade. Para isso, realizou-se uma investigação de caráter qualitativo cujos sujeitos foram alunos e ex-alunos com necessidades especiais que utilizavam o serviço de apoio didático do Laboratório de Acessibilidade da Biblioteca Central da Universidade Estadual de Campinas. A amostra contou com nove estudantes e a coleta de dados foi realizada através de entrevistas semiestruturadas, gravadas com o consentimento dos entrevistados. Para a análise, os dados foram agrupados de acordo com núcleos temáticos. Um dos aspectos relevantes do estudo foi a identificação de sentimento de insatisfação com a política de acessibilidade da universidade que tem dificuldade de implementar ações mais pontuais de inclusão, reflexo da nossa sociedade, que está estruturada para as pessoas "normais", e ainda não assimilou os conceitos de acessibilidade e desenho universal que devem contemplar toda a diversidade humana.

PALAVRAS-CHAVE: Inclusão, Acessibilidade, Necessidades Especiais, Diversidade.

\section{1 - INTRODUÇÃO}

Nas últimas décadas, as discussões sobre a questão da deficiência no Brasil vêm sendo recorrentes, observando-se preocupação com a inclusão e com a garantia de direitos das pessoas deficientes, cabendo considerar que em um passado recente tais

\footnotetext{
${ }^{6}$ Docente do Curso de Fonoaudiologia e do Programa de Mestrado Saúde, Interdisciplinaridade e Reabilitação do CEPRE / FCM / UNICAMP, e-mail: zeliaz@fcm.unicamp.br.

${ }^{7}$ Fonoaudióloga, graduada no Curso de Fonoaudiologia/ CEPRE/ FCM/ UNICAMP. Revista Serviço Social \& Saúde. UNICAMP Campinas, v. IX, n. 10, Dez. 2010
} 
pessoas eram pouco compreendidas e estigmatizadas, sendo-lhes reservados serviços de reabilitação, educação e trabalho em ambientes especiais.

Embora tais situações ainda não estejam totalmente superadas, já é possível vislumbrar um discurso mais condizente com o presente momento do processo civilizatório, ou seja, a inclusão de pessoas deficientes na sociedade com igualdade de direitos e oportunidades.

Este fato vem sendo impulsionado com a implementação de políticas públicas voltadas para a inclusão e garantia de direitos dos deficientes, graças aos dispositivos legais incorporados ao texto Constitucional no final da década de 80 , especialmente no âmbito da proteção social e suas materialidades saúde, educação, trabalho e assistência social (BRASIL, 1988).

Dessa forma, o direito à educação de todos os brasileiros, entre eles as pessoas deficientes, vêm procurando derrubar preconceitos e fazendo crer que a educação deste segmento populacional não é utopia (SANTOS, 2000; BRASIL/CORDE, 1994).

Diversas são as barreiras para uma pessoa com deficiência. No campo educacional há ainda muitas dificuldades a serem vencidas, à medida que o imaginário social deixe de enxergar a convivência com a deficiência como um tabu. Ainda hoje muitos professores consideram que o trabalho com esse grupo minoritário é impossível e algumas escolas alegam não estarem preparadas para receber tais alunos, a despeito da legislação que as obriga (REILY, 2004).

O levantamento censitário realizado no Brasil no ano de 2000 reporta que 24,5 milhões de brasileiros possuem algum tipo de deficiência, correspondendo a 14,5\% da população (NERI, 2003). Devido às desigualdades regionais, o Brasil convive com realidades distintas: algumas áreas com características de países em desenvolvimento e 
outras típicas de metrópoles de primeiro mundo. Nas áreas subdesenvolvidas, pode-se verificar a falta de informação da população e de políticas públicas que deem conta do saneamento básico e campanhas de vacinação que evitariam doenças causadoras de algumas deficiências, enquanto que em regiões mais desenvolvidas, observa se um expressivo e progressivo número de acidentes de trânsito e de trabalho sem deixar de salientar a crescente questão da violência urbana (SASSAKI, 2001).

O termo acessibilidade emerge na década de 40, com o surgimento dos serviços de reabilitação física e profisssional para designar a condição de acesso das pessoas deficientes. Contudo este termo vem sofrendo alterações ao longo do tempo e agregando novos significados. Na década de 80 , impulsionado pelas pressões do Ano Internacional das Pessoas Deficientes (SASSAKI, 1997), esse segmento populacional engajou-se em campanhas em âmbito mundial para alertar a sociedade sobre as barreiras arquitetônicas que restringiam o acesso à cidade, reivindicando e exigindo medidas no sentido de sua eliminação, bem como a adoção de um desenho mais acessível.

Os anos 90 marcaram posição de que a sociedade acessível só seria realidade com a incorporação do paradigma do desenho universal, segundo o qual, os equipamentos urbanos, ambientes e transportes deveriam ser projetados para todos indistintamente, e não apenas para as pessoas com deficiência.

Com o paradigma da inclusão (OMOTE et al., 2005) entendeu-se que a acessibilidade não se relaciona apenas às condições arquitetônicas, pois existem ainda barreiras de outras ordens a serem superadas. Tais barreiras não se restringem somente ao espaço físico, mas a outras dimensões, como as comunicacionais, as digitais, as metodológicas, instrumentais, programáticas e as atitudinais (SASSAKI,1997).

A acessibilidade de pessoas com algum tipo de deficiência à universidade foi impulsionada em 1.999, em decorrência de portaria do Ministério da Educação e 
Cultura (MEC - portaria $\left.n^{\circ} 1679 / 99\right)$, que imputou às universidades a responsabilidade no atendimento das necessidades de seus alunos através da criação de serviços que garantam o acesso dessa população (BRASIL, 1999).

Segundo Sassaki (1997), até o início da década de 80, diversas situações colaboravam para que estas pessoas deixassem de atingir as universidades, entre elas a falta de acesso à educação básica, a serviços de reabilitação e aparelhos especiais, os aspectos ligados às dificuldades financeiras, ao transporte coletivo além do desconhecimento dos direitos relativos à pessoa com deficiência.

O processo de inclusão deve se fundamentar na igualdade, na participação e na construção do espaço social. Portanto, uma universidade que pretenda assegurar o direito das pessoas com necessidades especiais, dando-lhes a garantia de acesso, ingresso e permanência, deve procurar eliminar todas e quaisquer barreiras que possam existir.

A Universidade Estadual de Campinas (UNICAMP), nos últimos anos vem implementando varias iniciativas para tornar os espaços construídos mais acessíveis aos deficientes, garantindo-lhes a cidadania e o acesso ao meio acadêmico. Todavia, visto a escassez de investigações sobre este tema, pouco ainda se sabe sobre o impacto dessas ações na vida dos estudantes e as percepções dos universitários deficientes sobre a acessibilidade nos espaços da universidade.

Para analisar esta questão, este estudo buscou conhecer o ponto de vista dos estudantes universitários deficientes da UNICAMP sobre as condições de acessibilidade da Universidade, identificar a adequação dos espaços e o tratamento por eles recebido, bem como verificar os fatores que interferem no desempenho acadêmico. 


\section{2 - MÉTODOS}

As informações aqui apresentadas foram resultantes de pesquisas qualitativas realizadas com alunos e ex-alunos com necessidades educacionais especiais. O estudo teve como cenário a Universidade Estadual de Campinas e contou com uma amostra de nove (9) estudantes universitários que aceitaram participar voluntariamente da pesquisa, respeitando-se o protocolo ético.

Como não há na universidade um banco de dados sobre os estudantes com necessidades especiais, justamente para preservar sua identidade, optou-se por contatar aqueles estudantes que utilizavam o serviço de apoio didático do Laboratório de Acessibilidade da Biblioteca Central da Universidade.

Os critérios de inclusão no estudo foram: ser ou ter sido aluno regular da UNICAMP, apresentar alguma necessidade educacional especial e assinar o termo de consentimento informado.

A coleta de dados foi realizada através de entrevistas semiestruturadas, gravadas com o consentimento do sujeito. O questionário apontava para uma avaliação da acessibilidade na universidade, as principais barreiras encontradas, as redes de apoio, as dificuldades didáticas, a inclusão na universidade, a discriminação e as mudanças que consideravam necessárias para tornar o ambiente universitário mais acessível.

Para a análise, os dados foram transcritos e agrupados em categorias de acordo com os núcleos temáticos supracitados. O projeto foi aprovado pelo Comitê de Ética da Faculdade de Ciências Médicas da UNICAMP. 


\section{3 - RESULTADOS E DISCUSSÕES}

\section{Características da amostra:}

Observou-se que 55\% (5) dos entrevistados eram do sexo masculino, sendo quatro deficientes visuais (1 cego e 3 com baixa visão) e um deficiente físico (tetraplégico). Dos estudantes do sexo feminino (45\%) verificou-se dois cegos e dois com deficiência física (paralisia cerebral e má formação).

A faixa etária variou de 22 a 48 anos, com idade média de 35 anos. Dois destes alunos cursavam a graduação e sete encontravam-se em programa de pósgraduação nas mais diversas áreas do saber: Física, Matemática, Artes, Educação, Economia, Jornalismo e Engenharia Civil.

A maioria dos estudantes residia no município de Campinas $(66,7 \%)$ e os demais eram provenientes de outras cidades do Estado de São Paulo. Quanto à situação civil $67 \%$ declaravam-se solteiros e $33 \%$ casados.

Da amostra entrevistada $89 \%$ referiram ter renda própria proveniente de atividade profissional ou bolsa fornecida por órgãos de fomento, sendo que somente um deles declarou ser dependente de familiares. A renda desses alunos variou de 2 a 14 salários mínimos, sendo, portanto a maioria constituída de alunos de classe média, que não dependem de benefícios assistenciais específicos para pessoas deficientes (Benefício de Prestação Continuada).

\section{Análise dos dados qualitativos}

Apesar das várias iniciativas que vêm ocorrendo na Universidade Estadual de Campinas para tornar os espaços mais acessíveis aos deficientes, garantindo cidadania e acesso ao meio acadêmico, ainda sabe-se muito pouco sobre o que pensam os universitários deficientes quanto a inclusão e a acessibilidade na universidade e quais os fatores limitantes ou barreiras encontradas para esta inclusão. 
Assim a reflexão sobre a acessibilidade no ensino superior a partir da realidade vivenciada pelos participantes da investigação, indicou o quanto esse tema é realmente amplo e complexo. A partir dos achados foi possível estabelecer seis núcleos temáticos ou categorias de análise, que buscaram envolver os aspectos abordados nas entrevistas: Acessibilidade na Universidade, Barreiras encontradas, Inclusão e discriminação, Redes de apoio, Dificuldades didáticas e tecnológicas, Mudanças a serem implementadas.

\section{Acessibilidade na Universidade}

A universidade constitui um lócus privilegiado para a implantação de acessibilidade por envolver diversas áreas do saber e distintas categorias profissionais sendo, portanto, um espaço multidisciplinar formador de opinião pública.

A questão da acessibilidade não é um problema somente de grupos minoritários, como está no imaginário das pessoas e sim uma situação que pode ser vivenciada por todos (CARDOSO, 1996).

A ausência de acessibilidade na sociedade não é um problema apenas das pessoas que apresentam alguma deficiência, mas um problema coletivo, pois sua falta discrimina e segrega as pessoas com deficiência, sendo fundamental para a qualidade de vida e para a inserção na sociedade com oportunidades iguais.

Na categoria "acessibilidade na universidade" agrupou-se dados observados na fala da maioria dos entrevistados, que referiram que a acessibilidade na UNICAMP ainda hoje é muito deficitária e reconhecem que as universidades estão começando a se adequar para receber pessoas com deficiência. Tais relatos refletiram a imagem de que a UNICAMP vem se preocupando e incentivando iniciativas para tornar seus espaços 
mais acessíveis, garantindo a cidadania e o acesso ao meio acadêmico, todavia esse processo vem ocorrendo de forma lenta e gradual, com pouca visibilidade, e ainda há necessidade de aprimorar e estender esses serviços e recursos.

Dentre as iniciativas da UNICAMP na configuração de ambientes inclusivos, a "Comissão Permanente de Vestibular - CONVEST", vem se preocupando com a acessibilidade no momento do ingresso de pessoas na Universidade, para oferecer um vestibular acessível às pessoas com deficiências visual, auditiva e física, proporcionando um espaço acessível e adaptações tecnológicas para a realização das provas (MANTOAN et al., 2005).

Este fato foi referido pelos entrevistados como uma importante iniciativa da Universidade que, no entanto, não deixaram de fazer suas críticas por entenderem que tais ações têm se limitado somente ao momento do vestibular.

“[...] o deficiente tem todas as condições (na hora) de prestar vestibular, mas muitas vezes o Instituto (que ele vai cursar) não está preparado para receber aquele aluno, então é muito complicado."

“[...] a acessibilidade na universidade é um processo [...] já foi pior em relação aos acessos e recursos a permanência do aluno, que eram super escassos. A criação do $\mathrm{LAB}$ da $\mathrm{BC}$ facilitou a permanência do aluno, mas esse processo é lento e está em construção e depende do esforço tanto da Universidade quanto do aluno."

Conforme o discurso dos próprios alunos, a acessibilidade no ambiente universitário é percebida ainda como muito deficitária visto que somente recentemente se observa preocupação com a adequação do espaço físico para receber pessoas com deficiências. 
“[...] a universidade é adequada para pessoas consideradas normais, construída para pessoas normais $[\ldots]$ deficientes físicos encontram dificuldade para se locomover na universidade."

\section{Barreiras encontradas}

Nesta categoria, as barreiras mencionadas são de diferentes naturezas, e devem ser superadas conforme a especificidade de cada caso. À medida que os estudantes vão fazendo parte do contexto universitário, vivenciam situações e circunstâncias que exigem mudanças de estratégias que envolvem não só o aluno, mas os diferentes sujeitos que compõem a comunidade acadêmica (MANZINI et al., 2002).

Se por um lado há dispositivos legais de acesso e permanência dos estudantes na universidade, por outro, a partir dos relatos pode se observar dificuldades encontradas, desde aquelas referentes à informação até as barreiras arquitetônicas e de atitude das pessoas em relação à deficiência. Desta forma, faz-se necessário uma maior adequação dos ambientes físicos, do mobiliário, a colocação de corrimãos, adaptação de banheiros, bebedouros e telefones, colocação de rampas e elevadores de acesso, além da articulação dos vários serviços disponíveis para atender estes estudantes, uma vez que estas situações são citadas como barreiras que dificultam o cotidiano acadêmico do estudante. Cabe ressaltar ainda a importância de ações informativas e de conscientização da comunidade universitária sobre as diversas deficiências. São consideradas barreiras:

“[...] as barreiras arquitetônicas: faltam rampas, elevadores, calçadas, muitas escadas, portas estreitas, portas de banheiros inacessíveis. Dificuldade de locomoção de um Instituto para o outro."

“[...] a atitude que os professores e funcionários tem para com os deficientes." 
“[...] falta de material em Braille, falta planejamento pedagógico para receber o material adequadamente."

\section{Inclusão / Discriminação}

A política de inclusão tem se preocupado com a questão da sociabilidade dos sujeitos inseridos em salas de aulas regulares, como se só isso bastasse.

Definir inclusão a partir de uma educação acessível compreende construir um olhar criterioso para organizar todas as condições necessárias para a Educação Inclusiva de Ensino Superior que possibilite a todos os alunos independente de qualquer situação todas as condições necessárias de acesso e permanência na universidade (SANTOS, 2000).

O movimento social de inclusão teve início na década de 80 e no Brasil foi impulsionado na década de 90, a partir dos paradigmas da Declaração de Salamanca (CORDE, 1994), que constituiu um marco importante para a educação inclusiva respeitando-se as características do indivíduo.

No que se refere à inclusão na universidade, a maioria dos entrevistados referiram que sua inclusão deu-se com muito esforço devido às barreiras arquitetônicas e atitudinais, pois ainda percebem o preconceito de algumas pessoas que subestimam os deficientes considerando-os incapazes.

Outro aspecto que apareceu com frequência no discurso dos estudantes com deficiência foi que estão cientes da responsabilidade dos alunos que muitas vezes abrem os caminhos, não devendo esperar somente que as medidas desejáveis venham de cima.

Observou-se ainda nos relatos dos entrevistados, um sentimento de certa "má vontade da universidade" em resolver os problemas arquitetônicos, o que já denota uma forma de discriminação. Outros referem nunca terem sentido qualquer tipo de discriminação na universidade, e sim fora dela, o que pode ser explicado por ser a Revista Serviço Social \& Saúde. UNICAMP Campinas, v. IX, n. 10, Dez. 2010 
universidade um espaço propício para a disseminação e divulgação do conhecimento também relativo à acessibilidade (MAZZONI et al, 2001) com maior grau de aceitação e tolerância às diferenças.

Um aspecto que sobressaiu nos achados foi o não cumprimento dos dispositivos legais e a falta de articulação entre os estudantes, a DAC - Diretoria Acadêmica, os institutos, os coordenadores de cursos e os professores, refletindo-se nas condições de acesso à aprendizagem, evidenciando certa discriminação parcial da universidade.

“[...] eu senti que houve uma má vontade em resolver a questão da acessibilidade física, porque minha sala era no segundo andar do departamento [...] e ficavam enrolando, jogando pra lá e pra cá e não tomavam atitude [...] isso encarei como discriminação." “[...] eu imaginava que preconceito não existia, que nunca ia acontecer comigo assim eu imaginava que minha capacidade fosse suficiente para que conseguisse fazer as coisas $[\ldots]$ acham que a gente não é capaz, alguns professores tentavam facilitar dizendo: não, não você não precisa fazer isso [...] e outros exigem demais para fazer com que a gente se sinta incapaz." “[...] às vezes na tentativa de se proteger se discrimina, tudo que difere, discrimina."

\section{Redes de Apoio}

Redes de apoio podem ser entendidas como os diversos grupos de pessoas com as quais o indivíduo mantém contato ou alguma forma de vínculo social. Segundo Gerhartd (2003) é na dinâmica das relações interpessoais que se encontra a base da estrutura das redes e das formas de entreajuda.

Ao considerar as redes de apoio não se pode deixar de mencionar a importância da família no desenvolvimento e na trajetória de vida destes estudantes. Para que estes jovens pudessem atingir à universidade, certamente a primeira e principal 
rede de apoio com que puderam contar foi o próprio núcleo familiar. Nos relatos foi possível observar que todos os entrevistados referiram receber total apoio dos familiares, em todos os aspectos da vida, especialmente no que se refere à busca da autonomia, embora muitas vezes as atitudes de proteção dos familiares não sejam por eles bem compreendidas.

“[...] eu me sinto bem na universidade, na minha família muitas pessoas até hoje não sabem lidar com a minha deficiência não conseguem me ver como uma pessoa capaz [...] na universidade eu não tenho isso, lá as pessoas acreditam em mim.”

Sobre as redes de apoio na universidade, os entrevistados manifestaram ter vivenciado uma experiência positiva e solidária dos colegas de classe que se prontificaram a ajudá-los, ora copiando a matéria, ora na convivência mais próxima, denotando amizade. Os professores, dentro do possível providenciavam os textos em Braille além de contarem com o suporte do Laboratório de Acessibilidade da Biblioteca Central na preparação do material. Há ainda alunos que relataram sentir necessidade de apoio psicológico buscando as associações de deficientes ou outros profissionais especializados.

A investigação evidenciou ainda que em muitos casos, os alunos deficientes receberam apoio e colaboração dos colegas de classe, possibilitando uma alternativa para suprir as eventuais falhas acadêmicas e as necessidades no processo de aprendizagem.

“[...] recebi auxílio dos colegas na copia da lousa, para mudar de sala, ir ao banheiro enfim dependendo da situação sempre tem alguém para me ajudar [...] preciso de apoio para andar."

"[...] dentro da universidade me sinto bem. No início os alunos queriam me ajudar, mas percebia que tinham receio de eu não conseguir terminar o curso, e muitas vezes, acabei ajudando os 
colegas, ensinando cálculo e física. Às vezes parece que o deficiente só recebe ajuda, mas muitas vezes eu fornecia a ajuda, eu surpreendi muita gente que me subestimou". (Relato de um aluno com visão subnormal)

"[...] colegas ajudavam na matéria, no estudo, professores muito solícitos [...] só falta mais informações para eles saberem lidar melhor com cada deficiência."

\section{Dificuldades didáticas e tecnológicas}

Nessa categoria, as dificuldades didáticas vivenciadas pelos deficientes visuais foram de ordens diferentes das experimentadas pelos deficientes físicos. No caso dos deficientes visuais, as dificuldades mais sentidas foram a falta de material, a escassez de bibliografia em Braille, a dificuldade de ler anotações na lousa, a falta de recursos tecnológicos como o scanner, o notebook, computadores com interface auditiva.

Os deficientes físicos, por sua vez relataram não encontrar dificuldades no aspecto didático, pois suas maiores limitações referem-se às barreiras arquitetônicas, dificultando e limitando o ir e vir. Estes achados mostraram ainda como é diversa a maneira como cada estudante percebe e relata sua dificuldade, sendo que cada um definiu as dificuldades encontradas com maior ou menor grau de importância, de acordo com sua deficiência e as condições vivenciadas em cada momento.

Outro dado observado refere-se a pouca utilização na universidade de recursos tecnológicos e do espaço digital, pois esse caminho poderia ser mais explorado com o intuito de atender as necessidades educacionais do aluno com deficiência.

A equiparação de oportunidades com os demais alunos muitas vezes foi mencionada como, por exemplo, no que se refere ao aumento de tempo para a realização de provas, ampliação da fonte utilizada, uso do computador em sala 
adequada, alterações para adequação de atividades, mas no entanto, sem a utilização de outros recursos tecnológicos já disponíveis atualmente.

“[...] há um alto número de leitura sem material preparado, necessito muito de recursos ópticos, que não encontro dentro da universidade."

"[...] tudo o que eu precisei teve que ser produzido, não havia materiais preparados, isso me prejudicava porque levava tempo para esse material ficar pronto, assim acumulando varias coisas para eu fazer em pouco tempo."

“[...] professores abriram exceções, por exemplo, no aumento de tempo de realização de provas, na possibilidade de usar notebook na prova."

\section{Mudanças a serem implementadas}

Nessa categoria, as mudanças para melhoria da acessibilidade na universidade, na visão dos alunos deficientes entrevistados, estão atreladas a uma mudança cultural da comunidade acadêmica e da sociedade, com a implementação de uma Política de Inclusão respeitando-se os direitos humanos, eliminando-se as barreiras e introduzindo o uso de tecnologias para facilitar o acesso aos textos. Isso seria possível com uma maior integração entre o DAC e as Faculdades, os Institutos, as Coordenadorias, dando uma maior assistência e apoio aos estudantes.

Outro aspecto mencionado foi quanto à aceitação do deficiente como uma pessoa com capacidade intelectual normal apesar das limitações físicas, contemplando toda a diversidade humana, que poderia estar melhor representada na universidade (cegos, surdos, deficientes físicos).

“[...] mas era o caso de eles - DAC - saberem quantos são e onde estão esses alunos, até pelo caso de poder atendê-los $[\ldots]$ 
mas não, eles preferem ignorar a presença de tais alunos na Universidade."

“[...] eu gostaria que as pessoas mudassem seu olhar em relação a deficiência, me vissem pela minha pessoa, pela minha capacidade, não pela minha deficiência, não pela minha limitação [...] o deficiente ainda é encarado como um estorvo."

"[...] é fundamental a universidade entrar na era de inclusão, que é uma tendência mundial, abrir os horizontes para que os responsáveis pelas faculdades tenham a mente aberta para fazer uma renovação, pois algumas faculdades ainda estão bem atrasadas nisso."

\section{CONCLUSÃO}

Um dos aspectos importantes identificados nesta investigação através dos depoimentos dos estudantes portadores de necessidades educacionais especiais foi a existência de um sentimento de insatisfação com a Política de Acessibilidade da Universidade Estadual de Campinas. O cotidiano destes alunos é rodeado de professores, administradores, discentes, funcionários e amigos, e envolve inúmeros aspectos que merecem atenção por parte de toda a Universidade a fim de que a acessibilidade seja garantida e as oportunidades de inclusão do estudante com deficiência na universidade sejam atingidas.

A UNICAMP como instituição formadora, ainda não conseguiu efetivar a acessibilidade na sua totalidade enquanto caminho para inclusão social. Os dados mostraram que esse segmento é bastante heterogêneo assim como o próprio contexto onde estão inseridos. Cabe, portanto à Universidade tentar viabilizar a todos os estudantes com necessidades educacionais especiais, condições reais de acessibilidade 
seja física, pedagógica, de comunicação, de sinalização, de atitudes, de equipamentos e de locomoção.

A partir destes dados, pode-se concluir que a universidade é o reflexo da sociedade, que está estruturada para pessoas "normais", e ainda não assimilou os conceitos de acessibilidade e de desenho universal que contemple toda a diversidade humana. Assim, a UNICAMP é vista pela maioria dos entrevistados como um espaço propício para o crescimento pessoal e profissional, um caminho para a realização de um sonho, que é a obtenção de um diploma de curso superior e ser finalmente reconhecido. Chegar à universidade é a realização de uma vitória pessoal, da superação dos limites. Cabe, portanto, à universidade corresponder a essas expectativas propiciando condições adequadas para a acessibilidade almejada.

"Não me sinto deficiente visual na universidade, tenho que dar conta dos trabalhos, provas, trabalhos dentro do cronograma $[\ldots]$ algumas disciplinas como fotografia, eu achava que não ia conseguir por ser cego, mas o professor insistiu, disse que eu seria capaz, que eu teria condições”. 


\begin{abstract}
The right of access at the regular education has been an important theme of discussions in this area. To assure not only the access, but mainly the rights of admission and permanence of handicapped people at the university it's not limited to the physical space or architectonic dimensions. This study aims to find out the perceptions of handicapped students at UNICAMP about accessibility conditions in the university. For this it was realized a qualitative research with students and alumni with special educational needs. The sample was made up by nine university students who use the Accessibility Laboratory of the University's Central Library. Data were collected through a semi-structured interview, taped with the permission of the interviewees. The analysis of the data was done through their separation in thematic fields. One of the relevant aspects of this study was the identification of a dissatisfactions regarding accessibility policies in the university, which still has a lot of difficulties to implement singular inclusion actions, a reflect of our society which is structured for "normal" people and has not assimilated a concept of accessibility and universal design that must includes all human diversity.
\end{abstract}

KEYWORD: Inclusion, Accessibility, Special Needs, Diversity

\title{
REFERÊNCIAS BIBLIOGRÁFICAS
}

BRASIL. Constituição (1988). Constituição da República Federativa do Brasil. Organização do texto: Juarez de Oliveira. 4. ed., São Paulo: Saraiva, 1990. 168 p. (Série Legislação Brasileira).

. Ministério da Justiça. CORDE. Declaração de Salamanca e Linha de Ação

sobre Necessidades Educativas Especiais. Brasília: CORDE, 1994.

. Ministério da Educação (1999a) Portaria n. 1.679 de 2 de dezembro de 1999. Diário Oficial da União, Brasília, n. 231-E, p. 20-1, 3 dez. Seção 1.

CARDOSO, M.A.C.C. Barreiras arquitetônicas no ambiente construído. 1996. 205 f.

Dissertação (Mestrado em Engenharia). Universidade de São Paulo, São Carlos. 
GERHARDT, T.E. Situações de vida, pobreza e saúde: estratégias alimentares e práticas sociais no meio urbano. Ciência \& Saúde Coletiva, v. 8, n. 3, p. 713-26. 2003. MANTOAN, M.T.E.; BARANAUSKAS, M.C.C. (Orgs.) Todos nós - Unicamp acessível: resultados da primeira oficina participativa do Projeto PROESP/CAPES, Campinas. 2005.

MANZINI, E.J. Um estudo sobre o acesso de pessoas com deficiência e sobre as barreiras arquitetônicas no Campus da Faculdade de Filosofia e Ciências da UNESP - Marilia. Relatório do Projeto Integrado - Grupo de Pesquisa Deficiências Físicas e Sensoriais. Marilia: UNESP, 2002.

MAZZONI, A.A; TORRES, E.F; OLIVEIRA, R.; ELY, V. H. M. B.; ALVES, J. B. M. Aspectos que interferem na construção da acessibilidade em bibliotecas universitárias. Ciência da Informação, Brasília, v. 30, n. 2, p. 29-34. 2001.

NERI. M. Diversidade: Retratos da deficiência no Brasil. Rio de Janeiro, FGV/IBRE, CPS. 2003.

OMOTE, S., OLIVEIRA, A. A. S., BALEOTti, L., MARTINS, S. E. S. O. Mudança de atitudes sociais em relação à inclusão. Paideia (Ribeirão Preto), n. 15, 387-98. 2005. REILY, L. Escola Inclusiva: linguagem e mediação. Campinas: Papirus, 2004.

SANTOS, M.P. Educação inclusiva e a Declaração de Salamanca: Consequências ao 2Sistema Educacional brasileiro. Revista Integração, v. 10, n. 22, p. 34-40. 2000.

SASSAKI, R.K. Inclusão: construindo uma sociedade para todos. Rio de Janeiro: Editora WVA. 1997. . Inclusão: A universidade e a pessoa com deficiência. Revista Nacional de Reabilitação, n. 20, p. 5-9. 2001. 